$\xi=$

\title{
Experimental Investigation of MQL Optimum Parameters in End Milling of AA6061-T6 using Taguchi Method
}

\author{
W.Safiei ${ }^{1 *}$,M.M.Rahman ${ }^{2}$, S.A.Rusdan ${ }^{3}$ \\ ${ }^{1}$ Faculty of Mechanical Engineering, Universiti Malaysia Pahang, 26600 Pekan, Pahang, Malaysia. \\ ${ }^{2}$ Faculty of Engineering Technology, Universiti Malaysia Pahang, Lebuhraya Tun Razak, 26300 Gambang, Pahang, Malaysia. \\ *Corresponding author E-mail: wahaizad.safiei@gmail.com
}

\begin{abstract}
Minimum Quantity Lubricants is a technique in supplying small quantity of lubricant into machining area which also part of green manufacturing approach that receive wide attention globally. The main driven of introducing MQL method was due to negative environmental impact which leads to safety and health issues of conventional coolant among workers especially in tool and mould industries. Besides, based on research findings, the MQL system has the capability for lubricating and cooling both work piece and cutting tool. In order to find the best solution for machining and also to enhance machining performance, first and foremost the MQL parameters must be controlled wisely as it has remarkable effects on lubricant coverage, droplets size and subsequently influence the machining performance. Nozzle angle, nozzle distance and MQL flow rate are the important parameters studied and surface roughness is the response parameter. Therefore, in this study, MQL optimum parameters were explored by minimizing surface roughness in end milling process using Taguchi L9 orthogonal method. Aluminum Alloy 6061-T6 was selected as work piece material. The results show that the best combination of MQL parameters in minimizing surface roughness was obtained at 30mm nozzle distance, 30 degree nozzle angle and $1.98 \mathrm{~mL} / \mathrm{min}$ MQL flow rate. Hence, based on this optimal condition, three confirmation runs were conducted. The margin error is acceptable which less than $10 \%$ and within prediction interval. This results can work as a base line guidance for any experimental that employ MQL system.
\end{abstract}

Keywords: Minimum Quantity Lubricants (MQL), End Milling, Optimum Parameters, Taguchi Method, Aluminum Alloy

\section{Introduction}

Metal cutting lubrication is crucial in metal removal process that relies on high intensity of shear deformation. Conventionally, flooded cooling is the only option which can removes the heat and lubricating the machining area. However, many negative impacts were reported such as environmental pollution, variety of diseases and hazardous working place as well as waste disposal issue [1]. Therefore, minimum quantity lubricant (MQL) approach has been explored since then to overcome these issues. This is because based on study done by General Motor, the MQL particle size is less than $5 \mu \mathrm{m}$ which can be considered as fine mist compared to $10 \mu \mathrm{m}$ particle size of flooded lubricant [2]. In terms of machining performance, MQL exhibits better performance than dry and flooded machining for surface roughness, tool life and cutting torque [3][4]. On the other hand, a total manufacturing cost can be reduced significantly when utilizing MQL in machining process [5]. Due to many advantages of MQL have been reported, it is important to explore its parameters that might improve machining performance. Based on a 2D steady-state computational fluid dynamics (CFD) analysis done by Najiha et al[6], the MQL nozzle performance was achieved by the three nozzles arrangement instead of one nozzle arrangement and also it works well for lubricating the rotating tool. Moreover, the position of nozzle in supplying the lubricant is vital for getting the optimum effect of MQL flow. According to Angulo et al [7], the correct nozzle position is facing the feed direction of the rotating tool. Erween et al [8] studied the effect of two different nozzle outlet diameter of $2.5 \mathrm{~mm}$ and
$3.0 \mathrm{~mm}$ on turning cutting force and cutting temperature. The $3.0 \mathrm{~mm}$ nozzle outlet diameter exhibits superior performance cooling due to wider cone angle and faster velocity. K.H. Park et al [9] studied the distribution of MQL droplets based on two independent variables which are distance from MQL nozzle and air pressure. The good coverage of lubricant was found at 12 psi air pressure and $30 \mathrm{~mm}$ nozzle distance. On the other hand, more droplets were seen when air pressure was increased. However, the droplet sizes were getting smaller when nozzle distance was increased. On the other hand, Taguchi method which is widely used in determining the optimum level of process parameter is applied in this study. Moreover, Taguchi is unique and powerful statistical method that can improves overall engineering quality and productivity [10]. The optimum level of the process parameter can be defined based on mean effect plots for means. Philip [11] investigated the best combination of three levels of dry cutting when milling Stainless Steel alloy using Taguchi L9 orthogonal method. The results show that the optimum cutting force was acquired when speed, feed rate and depth of cut were at level 3, level 1 and level 1 respectively. Similar analysis using Taguchi L9 orthogonal array also employed by Gaitonde et al [12] for study the optimal condition of turning parameters including MQL flow rate. The prediction value of response also able to acquire and the value can be compared with the actual value from the verification run. There are limited numbers of articles that have been published focusing on MQL optimization parameters. Instead, many scholars evaluated machining performance by using both MQL parameter such as MQL flow rate and machining parameters such as spindle speed, feed rate and depth of cut in their studies. Therefore, it is indispen- 
sable to explore MQL parameters and find its optimum parameters which can further enhance machining performance.

\section{Experimental Setup}

The main objective of this study is to determine the optimum MQL parameters in end milling process using Taguchi method. Even though the machining parameters are in optimum condition, the machining performance would not be in peak point should the best combination of MQL parameters are not obtained. Therefore, both MQL and machining parameters must be optimized prior to getting the best results of machining. Table 1 shows machining parameters that's fixed for all 9 runs in the experimental design. The MQL parameters studied were nozzle angle, nozzle distance and MQL flow rate. Surface roughness was the only response and the machined parts were measured using Surfcom surface roughness tester. In this study, Aluminium Alloy 6061-T6 was selected as work piece. The chemical composition of Aluminium Alloy 6061-T6 is shown in Table 2. The experimental design is based on Taguchi L9 orthogonal array with 3 factors and 3 levels as shown in Table 3.

Table 1: General Machining Parameters

\begin{tabular}{|l|l|}
\hline \multicolumn{1}{|c|}{ Variable } & \multicolumn{1}{c|}{ Set-up } \\
\hline Work piece & Aluminium Alloy 6061-T6 \\
\hline Specimen size & $100 \mathrm{~mm}$ x 100mm x 30mm \\
\hline Cutter size & $16 \mathrm{~mm}$ diameter \\
\hline Spindle Speed & $2000 \mathrm{rpm}$ \\
\hline Feed Rate & $100 \mathrm{~mm} / \mathrm{min}$ \\
\hline Depth of Cut & $3 \mathrm{~mm}$ \\
\hline Air Pressure & $0.5 \mathrm{Mpa}$ \\
\hline Inserts & Coated Carbide \\
\hline $\begin{array}{l}\text { Number of insert per } \\
\text { tool }\end{array}$ & 2 \\
\hline $\begin{array}{l}\text { Lubricant } \\
\text { Lubricant supply system }\end{array}$ & $\begin{array}{l}\text { Deionized Water : Ethylene Glycol } \\
(80 \%: 20 \%)\end{array}$ \\
\hline Number of nozzle & 3 \\
\hline Nozzle formation & $120^{\circ} / \mathrm{mozzle}$ \\
\hline Nozzle Angle & $30^{\circ}, 45^{\circ}, 60^{\circ}$ \\
\hline Nozzle Distance & $30,40,50 \mathrm{~mm}$ \\
\hline MQL Flow Rate & $0.66,1.32,1.98 \mathrm{~mL} / \mathrm{min}$ \\
\hline
\end{tabular}

Table 2: Aluminium Alloy 6061-T6 Chemical Composition (Weight\%) [1]

\begin{tabular}{|l|c|c|c|c|c|}
\hline Elements & $\mathrm{Si}$ & $\mathrm{Mn}$ & $\mathrm{Mg}$ & $\mathrm{Ti}$ & $\mathrm{Zn}$ \\
\hline Weight \% & $0.4-0.8$ & $\mathrm{Max}$ & $0.8-1.2$ & $\mathrm{Max}$ & 0.25 \\
& & 0.15 & & 0.15 & \\
\hline
\end{tabular}

Table 3: Factor and Level for MQL Parameters of Aluminum Alloy 6061T6

\begin{tabular}{|c|l|c|c|c|c|c|}
\hline \multirow{2}{*}{ Factor } & \multirow{2}{*}{$\begin{array}{c}\text { MQL } \\
\text { Parameter }\end{array}$} & Units & Type & $\begin{array}{c}\text { Level } \\
\mathbf{1}\end{array}$ & $\begin{array}{c}\text { Level } \\
\mathbf{2}\end{array}$ & $\begin{array}{c}\text { Level } \\
\mathbf{3}\end{array}$ \\
\hline $\mathrm{A}$ & $\begin{array}{l}\text { Nozzle } \\
\text { Angle }\end{array}$ & $\begin{array}{c}\text { Degree } \\
\left({ }^{\circ}\right)\end{array}$ & Numeric & 30 & 45 & 60 \\
\hline B & $\begin{array}{l}\text { Nozzle } \\
\text { Distance }\end{array}$ & $\mathrm{mm}$ & Numeric & 30 & 40 & 50 \\
\hline $\mathrm{C}$ & $\begin{array}{l}\text { MQL flow } \\
\text { rate }\end{array}$ & $\mathrm{mL} / \mathrm{min}$ & Numeric & 0.66 & 1.32 & 1.98 \\
\hline
\end{tabular}

Figure 1 and Figure 2 show the arrangement of MQL nozzles and the experimental setup in this study. There are 3 nozzles with 120 degree formation that are facing the cutting tool. This nozzle arrangement is not only providing a good lubricant coverage but also offered superior wettability especially on the edge of cutting tool.

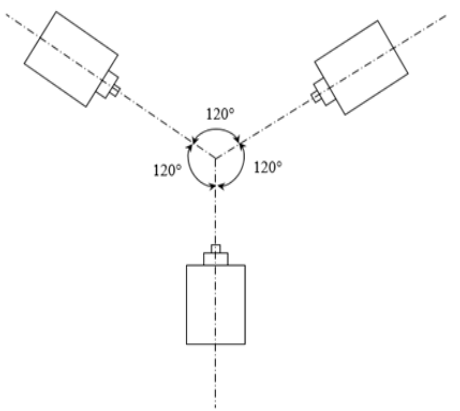

Fig. 1: Arrangement of MQL nozzles.

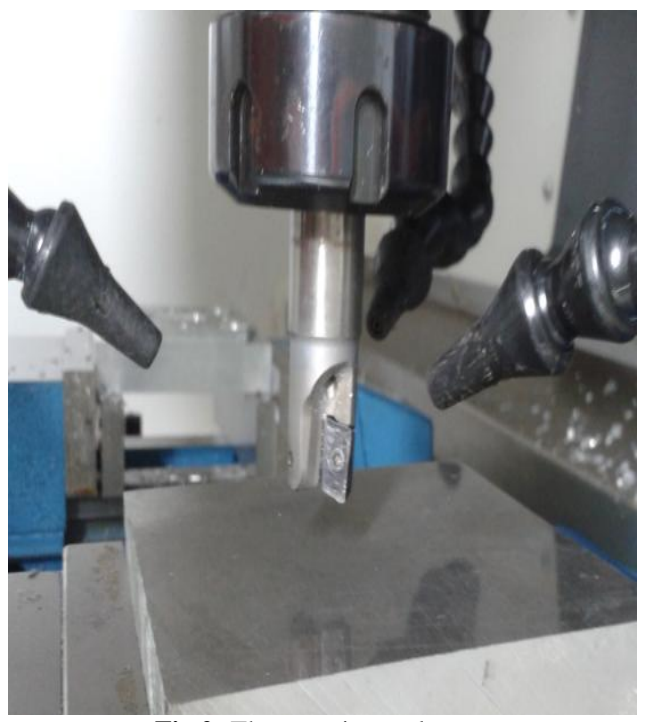

Fig.2: The experimental setup

\section{Experimental Results}

Table 4 shows the surface roughness results for the factors studied. The surface roughness data was replicated three times and the mean was calculated. The data obtained in this experiment were analyzed using Minitab software version 18. Moreover, the data were analyzed according to Taguchi approach.

Table 4: Experimental results of surface roughness for MQL parameter in end milling process

\begin{tabular}{|c|c|c|c|c|c|c|c|}
\hline Exp & \multicolumn{3}{|c|}{ MQL Parameter } & \multicolumn{4}{|c|}{ Surface Roughness, Ra } \\
\hline & $\begin{array}{c}\text { Nozzle } \\
\text { Angle } \\
\left({ }^{\circ}\right)\end{array}$ & $\begin{array}{l}\text { Nozzle } \\
\text { Dis- } \\
\text { tance } \\
(\mathbf{m m})\end{array}$ & $\begin{array}{c}\text { MQL } \\
\text { Flow } \\
\text { Rate } \\
\text { (mL/m } \\
\text { in) }\end{array}$ & $1^{\text {st }}$ & $2^{\text {nd }}$ & $3^{\text {rd }}$ & Mean \\
\hline 1 & 30 & 30 & 0.66 & $\begin{array}{c}0.80 \\
8\end{array}$ & 0.793 & $\begin{array}{c}0.72 \\
0\end{array}$ & 0.774 \\
\hline 2 & 30 & 40 & 1.32 & $\begin{array}{c}0.56 \\
1\end{array}$ & 0.534 & $\begin{array}{c}0.52 \\
6\end{array}$ & 0.540 \\
\hline 3 & 30 & 50 & 1.98 & $\begin{array}{c}0.43 \\
6\end{array}$ & 0.472 & $\begin{array}{c}0.43 \\
2\end{array}$ & 0.447 \\
\hline 4 & 45 & 30 & 1.32 & $\begin{array}{c}0.66 \\
7\end{array}$ & 0.593 & $\begin{array}{c}0.60 \\
0\end{array}$ & 0.620 \\
\hline 5 & 45 & 40 & 1.98 & $\begin{array}{c}0.42 \\
7\end{array}$ & 0.476 & $\begin{array}{c}0.36 \\
8\end{array}$ & 0.424 \\
\hline 6 & 45 & 50 & 0.66 & $\begin{array}{c}0.86 \\
7\end{array}$ & 0.898 & $\begin{array}{c}0.91 \\
6\end{array}$ & 0.894 \\
\hline 7 & 60 & 30 & 1.98 & $\begin{array}{c}0.40 \\
3 \\
\end{array}$ & 0.419 & $\begin{array}{c}0.43 \\
7 \\
\end{array}$ & 0.420 \\
\hline 8 & 60 & 40 & 0.66 & $\begin{array}{c}0.82 \\
8\end{array}$ & 0.835 & $\begin{array}{c}0.88 \\
6\end{array}$ & 0.850 \\
\hline 9 & 60 & 50 & 1.32 & $\begin{array}{c}0.57 \\
8\end{array}$ & 0.530 & $\begin{array}{c}0.50 \\
4\end{array}$ & 0.537 \\
\hline
\end{tabular}


Based on Taguchi analysis, minimum surface roughness was obtained at 30 degree, $30 \mathrm{~mm}$ and $1.98 \mathrm{~mL} / \mathrm{min}$ of nozzle angle, nozzle distance and MQL flow rate respectively. This can be seen in Figure 3 which shows the mean effects plot for the factors studied and the optimum level of factors when surface roughness is low. This is a combination of MQL optimization parameters. However, the nozzle distance of $30 \mathrm{~mm}$ and $40 \mathrm{~mm}$ exhibits the same results for the response. High probably, this is due to similar lubricant coverage on the cutting tool and work piece during machining and the effect of lubrication was not really significant between $30 \mathrm{~mm}$ and $40 \mathrm{~mm}$ of nozzle distance.

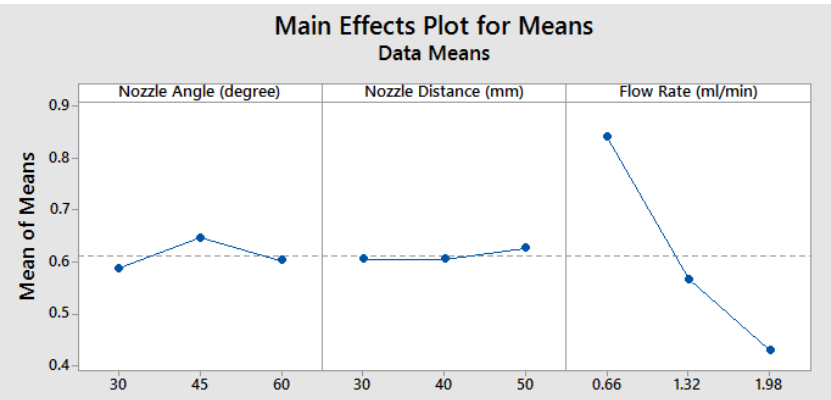

Fig. 3: Main effects plot for nozzle angle, nozzle distance and MQL flow rate.

The significant factor affecting the response studied is MQL flow rate, followed by nozzle angle and nozzle distance as shown in Table 5. Should the P-Value is less than 0.05, then the factor is considered significant. Otherwise, the factor studied is not significant. The $0.021 \mathrm{P}-$ Value of flow rate which less than 0.05 indicates that MQL flow rate is the most significant factor influencing machined parts surface roughness compared to other parameters. This finding is similar to The-Vinh and Hsu[14] and Murthy and Rajendran [15] which also found that the result of surface roughness was low at level 3 of fluid flow rate. Low surface roughness obtained at high lubricant flow rate because the good coverage of lubricant on the machining area. In addition, the droplet size increases with the increase of lubricant flow rate [16]. Subsequently, it helps in reducing friction forces and cutting temperature during end milling process. As a result, the machined surface is smooth as low shear deformation is required when removing the material.

Table 5: Analysis of variance for the factors studied

\begin{tabular}{|l|l|l|l|l|l|}
\hline Source & $\begin{array}{l}\text { D } \\
\text { F }\end{array}$ & Adj SS & Adj MS & $\begin{array}{l}\text { F- } \\
\text { Value }\end{array}$ & $\begin{array}{l}\text { P- } \\
\text { Value }\end{array}$ \\
\hline $\begin{array}{l}\text { Nozzle Angle (de- } \\
\text { gree) }\end{array}$ & 2 & $\begin{array}{l}0.00560 \\
0\end{array}$ & $\begin{array}{l}0.00280 \\
0\end{array}$ & 0.99 & 0.503 \\
\hline $\begin{array}{l}\text { Nozzle Distance } \\
(\mathrm{mm})\end{array}$ & 2 & $\begin{array}{l}0.00091 \\
5\end{array}$ & $\begin{array}{l}0.00045 \\
7\end{array}$ & 0.16 & 0.861 \\
\hline Flow Rate (ml/min) & 2 & $\begin{array}{l}0.26033 \\
6\end{array}$ & $\begin{array}{l}0.13016 \\
8\end{array}$ & 45.86 & 0.021 \\
\hline Error & 2 & $\begin{array}{l}0.00567 \\
7\end{array}$ & $\begin{array}{l}0.00283 \\
8\end{array}$ & & \\
\hline Total & 8 & $\begin{array}{l}0.27252 \\
8\end{array}$ & & & \\
\hline
\end{tabular}

\subsection{Confirmation Run}

The predicted value of surface roughness based on optimum MQL parameters was 0.398 . This value was generated by Minitab software version 18 . Hence, additional three experiments were performed to verify the value of surface roughness. The acceptance error for verification run is within $\pm 10 \%$ [17]. The details of confirmation run are shown below in Table 6 . Based on the confirmation run, it can be seen that the margin error below than $\pm 5 \%$ for all three runs. Thus, it is acceptable within prediction interval.
Table 6: Comparison between predicted values of MQL optimum condition versus actual value of verification experimental

\begin{tabular}{|l|l|l|l|l|}
\hline Experiment & $\begin{array}{l}\text { Predicted } \\
\text { Value }\end{array}$ & $\begin{array}{l}\text { Actual } \\
\text { Value }\end{array}$ & Residual & \% Error \\
\hline 1 & 0.398 & 0.402 & 0.004 & $0.9 \%$ \\
\hline 2 & 0.398 & 0.389 & -0.009 & $-2.3 \%$ \\
\hline 3 & 0.398 & 0.419 & 0.021 & $5.0 \%$ \\
\hline
\end{tabular}

\section{Conclusion}

Through this study, it is clear that MQL parameters have remarkable effects to the machining performance. There are few parameters of MQL that should be controlled when employing the MQL system in supplying lubricant into the cutting zone. Thus, it is important to determine the best combination of MQL in attempts for maximizing machining performance. Hence, it can help to increase overall manufacturing efficiency. It can be concluded that the optimum MQL parameters based on this study were obtained at $30^{\circ}, 30 \mathrm{~mm}$ and $1.98 \mathrm{ml} / \mathrm{min}$ of nozzle angle, nozzle distance and flow rate respectively. The percentage error between the predicted value and actual value of confirmation run is acceptable which below than $\pm 10 \%$. Therefore, these findings are really significant and helpful for any machining experimental setup that employ MQL system. For future works and recommendations, other MQL parameters like nozzle diameter and air pressure can be explored. Moreover, other machining responses such as cutting temperature and cutting force also can be evaluated as well.

\section{Acknowledgement}

The authors gratefully acknowledge the support of Universiti Malaysia Pahang for providing research grant RDU1703135.

\section{References}

[1] L. T. Tunc, Y. Gu, and M. G. Burke, "Effects of Minimal Quantity Lubrication (MQL) on Surface Integrity in Robotic Milling of Austenitic Stainless Steel," in Procedia CIRP, 2016, vol. 45, pp. 215-218.

[2] B. L. Tai, D. A. Stephenson, R. J. Furness, and A. J. Shih, "Minimum quantity lubrication (MQL) in automotive powertrain machining," in Procedia CIRP, 2014, vol. 14, pp. 523-528.

[3] T. Aoyama, "Development of a mixture supply system for machining with minimal quantity lubrication," CIRP Ann. - Manuf. Technol., vol. 51, no. 1, pp. 289-292, 2002.

[4] M. Rahman, A. Senthil Kumar, and Manzoor-Ul-Salem, "Evaluation of minimal quantities of lubricant in end milling," Int. J. Adv. Manuf. Technol., vol. 18, no. 4, pp. 235-241, 2001.

[5] V. Upadhyay, P. K. Jain, and N. K. Mehta, "Machining with minimum quantity lubrication: a step towards green manufacturing," Int. J. Mach. Mach. Mater., vol. 13, no. 4, p. 349, 2013.

[6] M. S. Najiha and M. M. Rahman, "Experimental investigation of flank wear in end milling of aluminum alloy with water-based TiO2 nanofluid lubricant in minimum quantity lubrication technique," Int J. Adv. Manuf. Technol., vol. 86, no. 9-12, pp. 2527-2537, 2016.

[7] L. N. López De Lacalle, C. Angulo, A. Lamikiz, and J. A. Sánchez, "Experimental and numerical investigation of the effect of spray cutting fluids in high speed milling," Journal of Materials Processing Technology, vol. 172, no. 1. pp. 11-15, 2006.

[8] E. A. Rahim and H. Dorairaju, "Evaluation of mist flow characteristic and performance in Minimum Quantity Lubrication (MQL) machining," Meas. J. Int. Meas. Confed., vol. 123, pp. 213-225, 2018.

[9] K. H. Park, J. Olortegui-Yume, M. C. Yoon, and P. Kwon, "A study on droplets and their distribution for minimum quantity lubrication (MQL)," Int. J. Mach. Tools Manuf., vol. 50, no. 9, pp. 824$833,2010$.

[10] M. S. Phadke, Quality Engineering using Robust Design. 1989.

[11] D. P. Selvaraj, "Optimization of cutting force of duplex stainless steel in dry milling operation," in Materials Today: Proceedings, 2017, vol. 4, no. 10, pp. 11141-11147.

[12] V. N. Gaitonde, S. R. Karnik, and J. P. Davim, "Selection of optimal MQL and cutting conditions for enhancing machinability in 
turning of brass," J. Mater. Process. Technol., vol. 204, no. 1-3, pp 459-464, 2008.

[13] M. S. Najiha and M. M. Rahman, "Experimental study on minimum quantity lubrication in end milling of AA6061-t6 using TiAlN coated carbide tools," Int. J. Automot. Mech. Eng., vol. 11, no. 1, pp. 2771-2785, 2015.

[14] T.-V. Do and Q.-C. Hsu, "Optimization of Minimum Quantity Lubricant Conditions and Cutting Parameters in Hard Milling of AISI H13 Steel,” Appl. Sci., 2016.

[15] K. S. Murthy and I. Rajendran, "Optimization of end milling parameters under minimum quantity lubrication using principal component analysis and grey relational analysis," J. Brazilian Soc. Mech. Sci. Eng., 2012.

[16] D. Setti, M. K. Sinha, S. Ghosh, and P. V. Rao, “An Effective Method to Determine the Optimum Parameters for Minimum Quantity Lubrication ( MQL ) Grinding," no. Aimtdr, pp. 1-6, 2014.

[17] P. B. Patole and V. V. Kulkarni, "Optimization of Process Parameters based on Surface Roughness and Cutting Force in MQL Turning of AISI 4340 using Nano Fluid," in Materials Today: Proceedings, 201 